\title{
7. Sim. Ahã. É. Sei. Aquisição das respostas curtas verbais afirmativas por bilíngues simultâneos sueco-brasileiros ${ }^{1}$
}

Mary-Anne Eliasson

Stockholms universitet

\section{Introdução}

$\mathrm{Na}$ Suécia as pessoas comunicam-se predominantemente em sueco. Em Estocolmo, o sueco é a língua de uso majoritário da cidade. Por ser a capital do país, a cidade sempre acolheu pessoas estrangeiras, algumas de passagem, outras para ficarem por tempo indefinido. Desde a década de 50 que a Suécia vem recebendo grande quantidade de imigrantes (Hyltenstam I999:I2), o que influenciou o mapa linguístico, principalmente, dos centros urbanos. Nos dias de hoje, crescer em uma família com linguas mistas (mixed-lingual families ${ }^{2}$, Arnberg I98I) em Estocolmo é muito comum (Eliasson 2012:16).

No trabalho de Eliasson (2OI2) foi analisada a aquisição do português brasileiro $(\mathrm{PB})$ por oito crianças bilíngues simultâneas $(2 \mathrm{LI})$ português-sueco, residentes em Estocolmo. Estas crianças crescem em famílias com línguas mistas ${ }^{3}$ com pai sueco e mãe brasileira, em um ambiente onde o PB é adquirido principalmente através do input materno durante seus primeiros anos de vida. O PB é por isso considerado a sua lingua mais fraca (LFr) (Schlyter I993) e levanta-se a hipótese de uma possível transferência da gramática da língua sueca na aquisição do português.

Foi observado que as crianças evitam certas formas gramaticais do português, ou então acabam por manter uma forma padrão por tempo prolongado 4 ao comparar o seu processo aquisicional com o de crianças PBLI (Eliasson 20I2:I84). A gramática do português brasileiro

Como citar este capítulo:

Eliasson, Mary-Anne, Sim. Ahã. É. Sei. Aquisição das respostas curtas verbais afirmativas por bilíngues simultâneos sueco-brasileiros. In: Engwall, Gunnel \& Fant, Lars (eds.) Festival Romanistica. Contribuciones lingüísticas - Contributions linguistiques Contributi linguistici - Contribuições linguísticas. Stockholm Studies in Romance Languages. Stockholm: Stockholm University Press. 20I 5, pp. I3 I-I 59. DOI: http:// dx.doi.org/ıo.16993/bac.g. License: CC-BY 
como a língua mais fraca (PBLFr) é adquirida de forma mais lenta, mas não considerada desviante. Percebe-se que faltam às crianças $2 \mathrm{LI}$ contextos propícios para desenvolverem a pragmática da língua, pois apresentam dificuldade em empregá-la em contextos interacionais específicos.

O emprego das respostas curtas verbais afirmativas e da partícula assertiva sim encontra-se em uma situação de interface onde a gramática e a pragmática do $\mathrm{PB}$ entram em conflito com a pragmática do sueco na produção do PBLFr apesar de as crianças terem adquirido a flexão verbal de pessoa (INFL) (Eliasson 20I2:I2I-I25). Partindo deste pressuposto, será feita uma apresentação dos resultados encontrados em Eliasson (20I2), cujo enfoque teórico é de cunho gerativista, seguindo a tradição dos estudos sobre aquisição bilíngue $(2 \mathrm{LI})$ feitos por Meisel (I994; 200I) e Schlyter (I993 I994).

\section{Os informantes}

Nas primeiras gravações feitas para a coleta de dados foram entrevistadas oito crianças entre as idades de 3; I I, O a 7; IO,I 6 (Eliasson 20I2). As gravações seguiram por um período de I 8 meses. Para o atual artigo a apresentação de dados foi restringida aos resultados da análise da linguagem das informantes Anna (7; IO,I 6 a 8;2,20) e Maria (6;I,I 6 a $6 ; 6, \mathrm{I} 3$ ), e a três das entrevistas feitas com cada uma delas (vide Tabela I, a seguir).

Anna e Maria foram escolhidas por terem uma situação familiar que apresenta traços bastante semelhantes: mães do sudeste brasileiro com formação acadêmica, que trabalham com assuntos diretamente ligados ao Brasil e à língua portuguesa, não tendo sido registrado nenhum sinal de regressão em seu português (Lund 2003); pais suecos, de Estocolmo, com formação acadêmica e com uma atitude positiva em relação ao Brasil e ao uso do $\mathrm{PB}$ no ambiente familiar com as crianças, e em geral também; irmãos três anos e meio mais novos, que na época entendem, mas não falam português, sendo que as crianças falam sueco entre si. As duas meninas nunca tiveram dificuldade em separar as duas línguas, mas assim que entraram para o jardim de infância o sueco passou a ser nitidamente a sua lingua mais forte (LFo). No jardim de infância são introduzidas a contextos interacionais diversos, aos quais não têm acesso em PB na sua cidade natal, pois a interação no cotidiano destas meninas é unimonitorado por suas mães (Eliasson 20I2:3 I-33). 


\section{O corpus analisado}

As três entrevistas selecionadas de cada uma das informantes foram realizadas com o mesmo espaço de tempo e têm o mesmo formato. As meninas são entrevistadas pela Int(interlocutora), iniciando as sessões com uma curta apresentação de si mesmas; conversam a seguir sobre assuntos cotidianos como, por exemplo, escola, família e brincadeiras; seguem descrevendo as ilustrações de um livro sobre brincadeiras ao ar livre (Utelekar, de Heuninck 1989), e por fim, é feita uma revisão de vocabulário como a denominação de móveis, brinquedos, cores, partes do corpo e utensílios domésticos. Procura-se aqui conhecimentos ligados ao dia-a-dia e ao lar da criança, pois é levado em consideração o fato de o input materno restringir-se à interação familiar, o que torna o ambiente doméstico muito importante para as crianças $2 \mathrm{LI}$ em geral, pois é nele que vivenciam um contexto no qual o português (no caso de nossas informantes) pode predominar naturalmente, é nele que a mãe das crianças tem possibilidade de fornecer uma impressão linguística, situação esta destacada por Schlyter (I987).

O irmão mais novo de Anna, Oscar, participa das duas primeiras entrevistas feitas com a informante, sendo a terceira individual. No caso de Maria, as três entrevistas são individuais. A primeira entrevista registra o PB das informantes antes de passarem um mês com seus familiares no Brasil; a segunda registra o seu PB assim que voltam do Brasil; e a terceira registra o PB três meses depois da sua volta, onde é observado se os traços ativados durante a viagem se mantêm, não sendo verificado nenhum tipo de regressão na sua produção depois dos meses passados longe do contexto PBLI.

$\mathrm{Na}$ Tabela I encontram-se os resultados da contagem de MLUs das seis entrevistas que compõem este corpus. A contagem de MLU em estudos de aquisição bilíngue é usada como uma forma de comparar se as gramáticas das línguas adquiridas pela criança são adquiridas de forma equilibrada (Meisel I994 200I; Schlyter I993 I994; Bernardini 2003), ou se o desenvolvimento de uma das línguas regride quando a criança é exposta a algum tipo de mudança em seu ambiente como, por exemplo, mudança de país (Yukawa I997). O MLU é uma ferramenta que possibilita o acompanhamento passo-a-passo da aquisição de traços gramaticais.

Nos casos de Anna e Maria, a contagem do MLU é feita, também, para estabelecer o estágio ${ }^{6}$ do desenvolvimento linguístico no qual a aquisição do PBLFr das informantes se encontra. A contagem de MLU 
é interessante para o acompanhamento do desenvolvimento da complexidade gramatical da linguagem da criança até o nível 4.0, que equivale ao V Estágio de Brown (I973:55). A partir deste nível considera-se que a criança já tenha então adquirido a complexidade sintática da língua, resultando em orações completas.

Os componentes da Tabela I são (da esquerda para a direita): nome e idade das informantes; nome da entrevista correspondente; resultado da contagem do MLU para o português (PB), o sueco (S) e para as frases mistas $(\mathrm{TC})^{7}$ registradas; a quantidade de enunciados e a porcentagem de enunciados em cada registro (PB, S e TC); e por fim é apresentada a quantidade total de enunciados.

Tabela 1. As entrevistas de Anna e Maria

\begin{tabular}{|c|c|c|c|c|c|c|c|c|}
\hline \multirow{2}{*}{$\begin{array}{l}\text { Inform- } \\
\text { ante }\end{array}$} & \multirow{2}{*}{$\begin{array}{l}\text { Nome da } \\
\text { entrevista }\end{array}$} & \multicolumn{3}{|c|}{ MLU } & \multicolumn{3}{|c|}{ Enunciados } & \multirow{2}{*}{$\begin{array}{c}\text { Enunciados } \\
\text { total }\end{array}$} \\
\hline & & PB & $S$ & $\mathrm{TC}$ & PB & S & TC & \\
\hline $\begin{array}{l}\text { Anna } \\
7 ; \text { I0,I } 6\end{array}$ & A & 2,33 & 2,66 & 7 & $\begin{array}{r}\mathrm{I} 47 \\
(97,3 \%)\end{array}$ & $\begin{array}{r}3 \\
(2 \%)\end{array}$ & $\begin{array}{r}\text { I } \\
(0,7 \%)\end{array}$ & I 5 I \\
\hline $\begin{array}{l}\text { Anna } \\
7 ; \mathrm{II,2I}\end{array}$ & $\mathrm{A}_{5}-\mathrm{O}_{3}$ & 2,72 & I & 3 & $\begin{array}{r}253 \\
(98,8 \%)\end{array}$ & $\begin{array}{r}2 \\
(0,8 \%)\end{array}$ & $\begin{array}{r}\mathrm{I} \\
(0,4 \%)\end{array}$ & 256 \\
\hline $\begin{array}{l}\text { Anna } \\
8 ; 2,20\end{array}$ & A6 & 3,26 & - & 4,70 & $\begin{array}{r}\text { I } 53 \\
(82 \%)\end{array}$ & - & $\begin{array}{r}27 \\
(\mathrm{I} 8 \%)\end{array}$ & I 80 \\
\hline $\begin{array}{l}\text { Maria } \\
\text { 6;I,I6 }\end{array}$ & $\mathrm{M} 2$ & $2, I O$ & 2,54 & 3 & $\begin{array}{r}\mathrm{I} 24 \\
(6 \mathrm{I} \%)\end{array}$ & $\begin{array}{r}72 \\
(35 \%)\end{array}$ & $\begin{array}{r}8 \\
(4 \%)\end{array}$ & 204 \\
\hline $\begin{array}{l}\text { Maria } \\
6 ; 3,3\end{array}$ & $\mathrm{M}_{4}$ & 3,42 & 3 & 4,4 & $\begin{array}{r}3 \mathrm{I} 4 \\
(97,7 \%)\end{array}$ & $\begin{array}{r}6 \\
(\mathrm{r}, 8 \%)\end{array}$ & $\begin{array}{r}5 \\
(\mathrm{I}, 5 \%)\end{array}$ & 325 \\
\hline $\begin{array}{l}\text { Maria } \\
6 ; 6,13\end{array}$ & M6 & 3,76 & 3 & 6 & $\begin{array}{r}54 \\
(94,6 \%)\end{array}$ & $\begin{array}{r}2 \\
(3,4 \%)\end{array}$ & $\begin{array}{r}I \\
(2 \%)\end{array}$ & 57 \\
\hline
\end{tabular}

Observando os dados da Tabela I, no caso de Anna, o MLU do PB aumenta na entrevista feita logo após a sua volta a Estocolmo $\left(\mathrm{A}_{5}-\mathrm{O}_{3}\right)$ e continua aumentando durante os meses passados em Estocolmo (A6), passando de 2,33 a 3,26, ou seja: não há uma regressão, mas não alcança o nível 4.o. No caso de Maria ocorre o mesmo, um aumento contínuo, passando de 2, Io a 3,76, mas também não chega ao nível 4.o. Apesar de o MLU aumentar e a porcentagem do sueco (S) diminuir no decorrer das entrevistas, percebe-se um ápice quantitativo em relação ao número de enunciados assim que voltam a Estocolmo 
(entrevistas $\mathrm{A}_{5}-\mathrm{O}_{3}$ e $\mathrm{M}_{4}$ ). Mesmo as entrevistas A6 e M6 sendo mais espontâneas em sua estrutura, a intimidade com o $\mathrm{PB}$ em seu registro ativo mostra-se mais forte nas entrevistas $\mathrm{A}_{5}-\mathrm{O}_{3}$ e $\mathrm{M}_{4}$.

\section{Enfoque teórico}

O contato diário com o português LFr em Estocolmo, em ambiente familiar, é suficiente para acionar a concordância gramatical [AGR], que passa a fazer parte do português ativo das informantes durante sua estadia de um mês no Brasil, em ambiente PBLı. Esta continuidade dada à comunicação em português em ambiente familiar é suficiente, também, para que as crianças, não apenas mantenham o traço flexional ativado durante este período, mas para que este fenômeno gramatical passe a fazer parte da sua produção ativa, fixando-se em sua comunicação em português (Eliasson 20I2:I2I-I25).

Encontra-se um modelo na aquisição da flexão verbal no desenvolvimento linguístico das informantes $2 \mathrm{LI}$, que se diferencia do processo aquisicional da criança PBLi por ser mais lento. Na terceira entrevista (A6 e M6) é registrado o alcance de um desempenho semelhante ao LI (Eliasson 20I2:I2I). Em relação à situação de interface gramática/ pragmática supõe-se que o sistema sueco de emprego de respostas curtas $(\mathrm{RC})$ influencie a forma de interação das crianças $2 \mathrm{~L}_{\mathrm{I}}$.

Ao observar o desenvolvimento da aquisição da flexão verbal, Eliasson (20I2:9I-I25) registra que as crianças $2 \mathrm{LI}_{\mathrm{I}}$ apresentavam dificuldade quanto à implementação do modelo das respostas curtas assertivas positivas em português. O trabalho de Oliveira (2000) analisando a função das RCs verbais na aquisição do pronome nulo, foi usado como material contrastivo para a observação da aquisição do emprego das respostas curtas verbais pelas informantes $2 \mathrm{LI}$, e como apoio para a definição dos diferentes tipos de respostas curtas, assim como a tipos de frases interrogativas estas respostas correspondem. O desempenho das informantes foi comparado, também, com um corpus contrastivo, composto de entrevistas feitas com quatro crianças PBLI, com sete anos de idade cursando o primeiro ano do ensino básico no Brasil.

As qualidades acústicas, como a entonação e o ritmo da língua, são levadas em consideração na observação das RCs. Essas qualidades acústicas terão de fazer parte do repertório LFr das informantes para que possam reconhecer os diferentes tipos de interrogativas, visto que, no português, as interrogativas polares são marcadas apenas pela 
entonação do falante, tratando-se aqui de uma questão de interface entre a sintaxe e a fonologia (Kato 2002). Tanto a entonação, como o ritmo, apresentam variações dependendo da intenção do falante, existindo um modelo aceitável para estas variantes nas relações dimensionais dentro de cada língua (Fry I970:46).

No trabalho de Oliveira foi encontrada uma análise da aquisição das respostas curtas assertivas por crianças PBLI e da função destas na aquisição de INFL, incorporando esta categoria a três outras categorias funcionais: finiteness (finitude), AGR (concordância) e T (tense tempo). Segundo Meisel (I994:90) tanto AGR como T são dependentes da aquisição de finitude para serem adquiridos pela criança, apresentando assim uma hierarquia de aquisição onde a finitude aparece primeiramente marcada por AGR, sendo T adquirido mais tarde. Esta hierarquia aquisicional mostra-se ser uma característica considerada universal para a aquisição da linguagem (Choms-ky I982; Meisel I994; Oliveira 2000; Mioto, Silva \& Lopes 20Io; entre outros).

Segundo a teoria seletiva da aquisição da linguagem (Lightfoot I989), a criança desenvolve sua LI a partir de dados simples e robustos (Degree-o learnability) encontrados na língua-E do adulto (a língua-alvo da criança), para desenvolver a sua língua-I. A experiência acionadora estaria restrita a contextos sintáticos e a poucos elementos funcionais (previstos pela GU) o que torna a tarefa de adquirir uma língua menos complexa (mais viável) como foi ponderado por Carroll (I989:40I). Foi observado no desenvolvimento aquisicional de ambas as informantes, que estas estavam atentas quanto ao estímulo encontrado no ambiente PBLI e determinadas (cognitivamente maduras) a ativá-lo. Abre-se aqui um espaço para a fixação de [AGR], valor morfossintático incluído no parâmetro de finitude. [AGR], por sua vez, aciona também a marcação dos valores do parâmetro flexional, as condições para a marcação do sujeito nulo [+ sujeito nulo] e do [øSpec] de um IP, fenômeno este característico das RCs verbais (Kato I994; Oliveira 2000). Esta constatação não é controversa, pois na hierarquia da GG, o funcional [+AGR + T] sempre é marcado antes do lexical, o que em um IP no PB pode manifestar-se com [øSpec].

Segundo Holmberg, Nayudu e Sheehan (2009:65-66) o fato de o PB ser uma língua de sujeito nulo parcial, implica em que sejam encontradas restrições para o emprego do sujeito nulo na 3 ps, exigindo um antecedente explícito e sendo obrigatório o pronome pleno na introdução de um novo tópico. Já na primeira pessoa do singular (Ips) ${ }^{9}$ não há 
restrições para o emprego do pronome nulo, apesar de haver contextos onde esta forma se apresenta mais propícia (Oliveira 2000). No contato com o PBLı, no Brasil, as informantes são expostas a uma situação comunicativa que ativa não apenas a capacidade pragmática de empregar as respostas curtas, mas são também expostas a um ambiente que torna a gramática da LFr viável (Carroll I989), facilitada pelas condições de time e input (Pinker I984), em condições às quais as crianças PBLI também são expostas.

Com o apoio do trabalho de Oliveira (2000) será feita uma comparação da aquisição das RCs verbais por crianças PBLI e pelas crianças PBLFr.

\subsection{Emprego das respostas curtas e das confirmações alargadas em português}

Neste trabalho define-se por resposta curta (RC) as respostas compostas de uma palavra ou interjeição, incluindo também as confirmações alargadas, que possam conter algum traço enfático. As RCs podem servir como resposta a diferentes tipos de interrogativas. As mesmas definições descritas por Oliveira (2000:69) para os diferentes tipos de frases interrogativas serão empregadas na atual análise.

As interrogativas de foco estreito são as interrogativas [-IP], formadas apenas por um NP, um VP, um CP, ou, por exemplo, um PP:

(I)

$\mathrm{A}-\mathrm{Com}$ você?
$\mathrm{B}-\mathrm{E}$

As interrogativas de foco largo são formadas de IP (finiteness, AGR e T) e exigem uma frase verbal como RC:

(2)
A - Você canta?
$[+\mathrm{IP}]$
B - Canto.

Observando as definições do Quadro I, embaixo, fica claro que o PB apresenta preferência pelo uso do verbo finito ${ }^{\mathrm{II}}$, ao invés da partícula assertiva sim nas respostas assertivas positivas, distinguindo-se assim, nesta questão, de outras línguas românicas modernas, que se restringem ao uso da partícula assertiva: sí (espanhol), sì (italiano) ou oui (francês) (Oliveira 2000:83). Segundo Lemos (I975:29I), se não há a necessidade de marcar a resposta com o uso de um sim, a forma de concordar com o interlocutor em português é repetir o verbo auxiliar ou a forma simples do verbo usado na pergunta. Sendo assim, 
Quadro 1. Diferentes tipos de frases interrogativas

\begin{tabular}{ll}
\hline I. Polares: & A - Você sabe nadar? \\
& B - Sei. \\
2. De foco largo: & A - Saíram da cozinha também? ${ }^{\text {Io }}$ \\
[+IP] & B - Saíram. \\
3. De foco estreito: & $\begin{array}{l}\text { A - Não sei o que está acontecendo com } \\
\text { a minha filha? }\end{array}$ \\
\hline$[-\mathrm{IP}]$ & B - Comigo? \\
& A - É. \\
$\begin{array}{l}\text { 4. Declarativa } \\
\text { (Confirmação ou asseveração de } \\
\text { uma frase declarativa anterior) }\end{array}$ & B - É. \\
\hline
\end{tabular}

a ocorrência da partícula assertiva sim sem o acompanhamento de um verbo é muito rara, tanto no PB como no PE, segundo Carreira $\&$ Boudoy (I993:264).

Atualmente, o uso da partícula sim restringe-se às construções enfáticas e a construções denegativas (em ( $3 \mathrm{~d}$ ) e (3e), a seguir), sendo também usada na escrita ou em contexto estritamente formal no PB (Oliveira 2000:I79).

Seguem, abaixo, exemplos de frases que contém as diferenças de emprego entre RCs verbais e a partícula assertiva $\operatorname{sim}(3)$ :

(3)

a. O João não é feliz. (frase declarativa) ${ }^{\mathrm{I2}}$

b. É. Ele não é. (confirmação)

c. *É. Ele é. (denegação)

d. Ele é (feliz sim). (denegação)

e. É sim. (denegação) ${ }^{\mathrm{I}}$

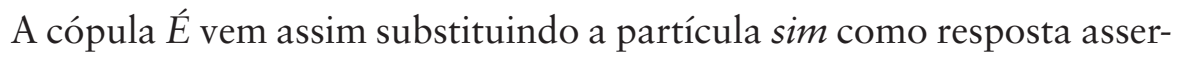
tiva, sendo usada apenas para confirmar a frase anterior $(3 \mathrm{~b})$, substituindo respostas do tipo verbal e empregada, frequentemente, como resposta a interrogativas polares, não podendo ter função denegativa quando usada por si só, como é visto em (3c) (Oliveira 2000:45-47). Para usar a cópula $E$ em função denegativa, exige-se a participação enfática da partícula sim, como em (3d) e (3e). 
A cópula É como marcadora de polaridade positiva vem substituindo a partícula assertiva sim como resposta às interrogativas com foco estreito [-IP] (Quadro I), ou então para confirmar um NP (Oliveira 2000:173):

(4)
A: A Anna?
B: É.

Devido ao fato de o uso da partícula sim, da cópula É e das frases verbais estarem diretamente ligadas a fatores pragmáticos, não é estranho que sejam detectadas dúvidas no registro linguístico das informantes 2Li em relação ao emprego destas formas. Leva-se, também, em consideração o fato de na LFo das crianças serem usadas duas partículas polarizadas ( $j a$ ou jo e nej) para estas respostas curtas mínimas, podendo ser adicionado um complemento verbal (resposta curta alargada) ou pronominal como elemento enfático:

Tabela 2. Esquema de emprego das partículas polares em sueco (Teleman, Hellberg, Andersson \& Christensen I 999a:752)

\begin{tabular}{lll}
\hline & Confirmação & Oposição \\
\hline Interrogativa & ja [jo:] & nej [nধj] \\
Interrogativa com negação & nej [nধj] & jo [ju:] \\
\hline
\end{tabular}

No modelo de respostas curtas em sueco ${ }^{14}$ são usadas duas partículas assertivas equivalentes ao sim: ja ([jo:]) ou jo ([ju:]). Como partícula negativa emprega-se o nej $([$ nej] $=$ não $)$. Essas são usadas para concordar ou discordar com a interrogativa polar colocada pelo interlocutor, diferenciando-se assim do modelo usado no $\mathrm{PB}$, que emprega frases verbais como resposta positiva. As interrogativas polares em sueco são denominadas interrogativas de submissão (Jörgensen \& Svensson 200I:I06), mas mais conhecidas por interrogativas sim/não (ja-nej-frågor, < trad: perguntas sim-não - Dahl I982:69), ou seja, uma pergunta à qual o ouvinte vai informar ao seu interlocutor se concorda, ou não, com o que foi proposto na interrogativa, podendo confirmar ou se opor ao que foi dito (Teleman et al. 1999b:748). Estas frases são compostas de uma frase interrogativa, cuja estrutura é sintaticamente fixa, iniciando com um $V_{\text {fin }}$ seguido pelo sujeito, a seguir um adverbial 
(opcional) para depois completar com o resto da frase (Teleman et al. I999b:73I):

(5)

$\begin{array}{clll}\text { A: Ska } & \text { vi } & \text { äta } & \text { snart? } \\ \text { Vfin } & \text { nós } & \text { comer.inf } & \text { logo? }\end{array}$

"Vamos comer logo?"

B: Ja

Sim

"Vamos"

Assim como no PB, são encontradas muitas variantes de emprego destas três formas de respostas curtas, como por exemplo: a repetição do nej para enfatizar a resposta; ou ja, jo e nej acompanhados por uma sentença declarativa (uma resposta alargada) que repete a proposição da interrogativa, de forma pronominal ou elíptica (Teleman et al. I999b:684); ou mesmo uma variedade de formas prosódicas e de pronúncia destas três partículas que dependem de contexto.

Independente da forma exigida pelo contexto, ou da variedade regional do sueco falado por um indivíduo, uma das três interjeições sempre inicia a resposta. Uma confirmação de uma interrogativa polar sempre é iniciada por um ja ( $\operatorname{sim})$, não havendo na LFo das informantes $2 \mathrm{LI}_{\mathrm{I}}$ uma forma equivalente às frases verbais como resposta positiva. Se a resposta em sueco se restringir ao emprego de uma só palavra, esta palavra será uma partícula assertiva afirmativa ou denegativa.

Temos aqui uma situação de interface sintaxe-pragmática à qual as informantes 2 LI não têm acesso no seu dia-a-dia bilíngue em Estocolmo, apesar de encontrarem o estímulo para esta forma de interação no input doméstico. As situações de interface mostram-se problemáticas para os aprendizes de uma nova língua ou de uma língua fora de seu contexto nativo, podendo também afetar o conceito de aceitação de um falante LI, pois a partir da aceitação de outro modelo discursivo (L2, LFo ou LFr) não é raro haver uma integração dos dois sistemas conhecidos pelo falante bilingue (Sorace \& Serratrice 2009). Se o emprego das RCs verbais se mostrar problemático para as nossas informantes $2 \mathrm{LI}$, poderíamos deduzir que, apesar de a morfossintaxe ter sido adquirida de forma LI, em situações de interface externa as crianças podem apresentar traços desviantes da norma PBLI, por serem estes desvios aceitos por suas mães que por sua vez conhecem e empregam o modelo 
discursivo da língua sueca diariamente. Pois, como é colocado por Pires \& Rothman (20II:77):

Childhood bilinguals often acquire one of the languages in a context in which it is only spoken by caregivers and/or by a limited sub-group of speakers within a larger community who may have already been exposed to the L2 for an extended time, and may show effects of attrition in their own LI.

Nota-se claramente, no estudo feito com as mães de nossos informantes, que é no discurso que mostram sinais de adaptação ao modelo sueco (Lund 2003). Além disso, há a aceitação de formas divergentes em contexto familiar (Eliasson 20I2), questão que acentua a necessidade de contato com o PBLi para que a LFr continue a se desenvolver em outros contextos interativos.

\subsection{As respostas curtas verbais}

As RCs empregadas como resposta às interrogativas polares no $\mathrm{PB}$ constam apenas de uma frase verbal, sendo esta constituída pelo verbo finito encontrado na frase interrogativa, flexionado de acordo com a pessoa gramatical em foco (com o sujeito nulo), ou pelos verbos de interligação (cópulas) ser e estar na 3 ps do presente do indicativo: É, (es)tá. As interrogativas polares são marcadas apenas pela prosódia no português (Kato 2002:324) sendo a sua estrutura sintática interpretada como marcada no complementizador por um morfema abstrato $[+\mathrm{Q}]$.

Segundo uma sugestão de Holmberg (200I) para o finlandês ${ }^{15}$, a construção destas respostas formadas apenas pelo verbo finito, em línguas de sujeito nulo parcial, pode apresentar na sua representação da surface structure (SS) o movimento do verbo para o domínio-C, sendo este movimento acionado pela polaridade do foco da frase interrogativa, excluindo nesta elevação o IP que contém tanto o objeto como o sujeito, tornando a estrutura da frase verbal impessoal ${ }^{16}$. Holmberg parte do princípio que as frases verbais no finlandês são derivadas de sentenças completas, nas quais o verbo finito é enunciado fora do IP, resultando em uma elipse do IP, ou seja: o IP fica vazio, sendo o seu conteúdo movido para o domínio-C como se houvesse uma equivalência do $V_{\text {fin }}$ à partícula assertiva sim, pois o movimento para o domínio-C adicionaria o valor discursivo afirmativo de sim à frase verbal. Como constata Oliveira (2000:222): “o sujeito nulo é possível quando o verbo sobe para uma posição mais alta no constituinte frasal”. 
Em Eliasson (20I2) o movimento para C não é visto como um movimento que faria das RCs verbais frases impessoais, pois se assim o fosse, teria de ser assumido que as RCs verbais seriam aprendidas pelas crianças em seu contexto discursivo, como uma frase fixa e não analisada, o que não é o caso, pois como será discutido a seguir, as frases verbais têm um sujeito referencial. No caso da RC verbal, o verbo sobe para o Spec do CP e o elemento que o modifica, como por exemplo, a partícula sim, se encontraria posicionada em C. O sujeito pleno ocorre assim quando o verbo não apresenta elementos que modifiquem seu conteúdo afirmativo, ou seja, quando o verbo mantém-se em IP. Vejamos as três representações abaixo:

(6)

a. $\left[{ }_{C P} \operatorname{FaçO}_{\mathrm{ij}}\left[\left[_{\mathrm{IP}} \varnothing\left[\mathrm{I}_{\mathrm{i}} \mathrm{t}_{\mathrm{j}}\left[_{\mathrm{VP}} \mathrm{t}_{\mathrm{i}}\right]\right]\right]\right]\right.$

b. $\left[_{C P} \operatorname{FaçO}_{\mathrm{ij}}\left[{ }_{\mathrm{C}} \operatorname{sim}\left[{ }_{\mathrm{IP}} \varnothing\left[\mathrm{t}_{\mathrm{i}} \mathrm{t}_{\mathrm{j}}\left[{ }_{\mathrm{VP}} \mathrm{t}_{\mathrm{i}}\right]\right]\right]\right]\right]$

c. $\left[{ }_{C P}\left[{ }_{I P} \operatorname{Eu}_{i}\left[\right.\right.\right.$ façO $\left.\left.\left._{j}\left[t_{V P} t_{i} t_{j}\right]\right]\right]\right]$

A frase verbal ocupa seu lugar em CP (exemplo 6a), posição [-A, $-\theta]$, assumindo um valor discursivo, mas sem deixar de ter um sujeito referencial, pois assim como o Yes carrega consigo o conteúdo da interrogativa polar na resposta (Yes, I do) a frase verbal também se refere ao conteúdo da interrogativa, como é dito pelo próprio Holmberg (200I) sobre o finlandês (acima): as frases verbais são derivadas de sentenças completas. Agora, quando a frase verbal contém mais informação, o sim ou o pronome pleno podem ser adicionados para enfatizar ou para denegar, mudando o tipo de afirmação atribuída à questão (como explicado no Quadro I).

Já no caso do emprego das cópulas É e (es)tá, não é atribuído o valor [+ pessoa] à frase verbal, tendo assim apenas a função de uma partícula assertiva, seguindo a proposta de Holmberg, sendo que o $E$ aparece acompanhado de resposta alargada em vários contextos, correspondendo assim ao modelo do $/ \mathrm{ja} / \mathrm{sueco}$, apresentando um traço equivalente ao da partícula assertiva positiva sim.

A seguir outro contexto no qual a frase verbal pode ser usada como RC:

(7) Resposta de Anna (A6)

Int: e como é que cê fez pro macarrão ficar preso lá?

A: colei

Encontra-se aqui um caso de RC verbal a uma interrogativa não-polar, na qual o verbo empregado é escolhido pela própria Anna, para explicar como resolveu a questão apresentada pela Int. O que nos interessa 
aqui é mostrar que Anna tem conhecimento da forma, referindo-se a si mesma flexionando o verbo na ips, fator que deixa bem claro o sujeito da frase. Mesmo se o caso fosse de um verbo flexionado na 3 ps, como no exemplo usado por Oliveira (2000:I32) apresentado abaixo (8), a frase verbal usada na RC não seria de interpretação problemática para um falante de $\mathrm{PB}$, não necessitando do emprego do pronome, para que o interlocutor soubesse que a pessoa em pauta é uma 2 ps, e não uma 3 ps ou uma Ipp:

A: eu te machuquei?

B: machucou

É interessante observar que, apesar de A (em (8)) usar a forma acusativa do pronome da 2 ps $(t u)$, a resposta de B se refere à 2 ps indireta (você), flexionada na $3 \mathrm{ps}$, sendo esta questão indiferente para o falante nativo de $\mathrm{PB}$. Os sujeitos das duas RCs verbais acima, são referenciais nulos. Oliveira (2000:I32) sugere então que "se a morfologia verbal no PB fosse de fato empobrecida, o sujeito da[s] frase[s] acima e das respostas curtas só seriam interpretáveis se lexicalmente preenchidos.”

A sugestão de Oliveira $(2000)^{17}$ vai contra o que é proposto por Holmberg et al. (2009:66), defendendo que:

Esta construção [RC frase verbal] pode ser derivada pelo movimento do verbo finito para o domínio-C, sendo este movimento acionado pela polaridade das características do foco, o que elimina a VP que contém tanto o sujeito como o objeto. Uma forte indicação de que este não é um caso de sujeito nulo é o fato de este ser insensível à pessoa do sujeito.

Dizendo assim que a flexão não é c-comandada, mas sim um fenômeno discursivo, onde o pronome é defectivo (ou pronome- $\varnothing$ ) e consta de características-ø válidas, de característica de Caso inválida e nada mais, faltando-lhe um índex referencial, ou seja, podendo o pronome, nesses casos, apenas ser lido como não temático (genérico ou arbitrário) e encontrados apenas em línguas de sujeito nulo parcial. Em resumo: a proposta de Holmberg et al. (2009) é plausível para o emprego das cópulas É e tá, mas não deve ser generalizada no PB. Os autores vêem como uma evidência para a sugestão acima o fato de o objeto (em alguns casos) ser pronunciado, mas não o sujeito, o que seria, segundo eles, uma forma agramatical no PB. Vêem como uma "complicação interessante" o fato de a estrutura Vi ele sim ser considerada aceitável em PB (Holmberg et al. 2009:67). Esta é uma estrutura corriqueira, 
sendo usada como uma confirmação, ou como uma resposta denegativa enfática, como em (9) na sequência fictícia abaixo:

(9)

A: O senhor tem certeza que viu o rapaz entrar na loja?

B: Vi ele sim (senhor).

O sim neste contexto é uma opção situacional de B, enfatizando a sua afirmação. Já a gramaticalidade das sentenças pode ser tratada pelo conceito de aceitabilidade, de como "soam" no contexto em que são empregadas (Oliveira 2000:I22), por isso não cabe aqui avaliar se esta expressão é gramatical, sabe-se apenas que é uma frase que consta do repertório do $\mathrm{PB}$, uma forma aceitável, comum e muito usada na fala informal do brasileiro.

Ao contrário do inglês, as crianças falantes de português têm de adquirir uma forma exclusiva para responder às interrogativas sim/não ao invés de uma estrutura para as interrogativas:

Despite very different input frequencies for the various clause types, there is no word order overgeneralization from one clause type to another. When acquiring word order for yes/no-questions, for example, children seem to focus exclusively on this clause type, and the word order of the clause types is irrelevant and constitutes neither evidence nor counterevidence. (Lightfoot \& Westergaard 2007:410).

Não é na frequência dessas frases no input das crianças $2 \mathrm{LI}$ que elas vão encontrar o gatilho desencadeador dessa forma, mas no fato de essa forma se encontrar em seu ambiente $2 \mathrm{LI}$, pois a criança mostra-se muito sensível ao input, mesmo quando a estrutura adquirida é pouco frequente, necessitando apenas de pequenas pistas para acionar diferentes estruturas (Lightfoot \& Westergaard 2007:407).

As frases verbais como RCs apresentam o fenômeno do sujeito nulo, diferenciando-se das frases declarativas que em sua maioria apresentam o preenchimento do sujeito. Agora, não se deve deixar de lado o fato de o PB continuar apresentando muitas ocasiões para o emprego do sujeito nulo em geral, por ser, primeiramente, uma língua de tópico proeminente, ou seja, uma língua que permite sujeito nulo encaixado (referencial $)^{18}$ e, também, pelas ocorrências do sujeito expletivo, o sujeito nulo de "orações sem sujeito" (Duarte 2003:I), como em: Chove! ${ }^{19}$

Observa-se ainda que aqui se encontram fenômenos de interface entre sintaxe e fonologia, como no caso das interrogativas polares $(\mathrm{sim} /$ não) onde basta a mudança de entonação, uma curva ascendente, para 
que a sentença seja interrogativa e não declarativa (Kato 2002:324), sendo estas as frases mais interessantes para uma análise, por terem uma estrutura que pode atrair o emprego do sim, ao invés de frases verbais nas RCs de nossos informantes $2 \mathrm{LI}$, podendo assim ser usada para verificar se há uma interferência da LFo.

\section{Análise das respostas curtas encontradas no corpus 2L1}

\subsection{Primeiras entrevistas}

As primeiras sequências a serem apresentadas foram tiradas das entrevistas feitas com os informantes Anna e Oscar ( $\mathrm{A}_{3}-\mathrm{O}_{2}$ ), e a outra com Maria (M2). Em $\mathrm{A}_{3}-\mathrm{O}_{2}$ a conversa se desenvolve a partir de uma pergunta colocada pela Int para os dois informantes, ao introduzir o tema das entrevistas e colocar o português em foco para as crianças: Você gosta de falar português?

Anna não responde a nenhuma das perguntas com o verbo finito que consta da frase interrogativa. Vê-se no desempenho de Anna, que ela parece ter conhecimento de o emprego da partícula sim como resposta afirmativa não ser usado no $\mathrm{PB}$. Na linha 8 (a seguir) Anna repete, na sua resposta, parte da pergunta que lhe é dirigida. Esta estratégia assertiva é também usada no PB informal, apresentando indícios de ter conhecimento do sistema assertivo da LFr.

Veja o desempenho de Anna no exemplo a seguir:

Tabela 3. Exemplos das entrevistas $\mathrm{A}_{3}-\mathrm{O}_{2}$ e $\mathrm{M}_{2}$

\begin{tabular}{|c|c|}
\hline Anna $(7 ; 10,16)$ & $\operatorname{Maria}(6 ; 1,16)$ \\
\hline I. Int: éle a Anna? & $\begin{aligned} \text { I. Int: } & \text { que gostoso e cê vai } \\
& \text { bastante pra piscina? }\end{aligned}$ \\
\hline 2. A: ahã & 2. $\mathrm{M}: \quad \mathrm{m}: \mathrm{m}: \uparrow$ \\
\hline 3. Int: você gosta de falar português? & 3. Int: é: cê sabe nadá? \\
\hline 4. A: m: $\underline{\text { ahá }}{ }^{20}$ & 4. M: $\quad \underline{\operatorname{sim} \downarrow}$ \\
\hline 5. Int: gosta? & $\begin{array}{l}\text { 5. Int: e cê tem amigas lá? amigas? } \\
\text { amigos? }\end{array}$ \\
\hline 6. A: $\quad \underline{\text { ahã }} \uparrow$ & 6. M: muitos \\
\hline $\begin{array}{l}\text { 7. Int: você acha que vai ser bom ir } \\
\text { pro Brasil agora? }\end{array}$ & \\
\hline 8. A: $\quad \underline{m}$ : vai ser bom & \\
\hline
\end{tabular}


No corpus composto de entrevistas com crianças PBLI foi registrada uma sequência com Rosa e Zé semelhante à sequencia de Anna (grifada):

(Iо)

I. Int: e você é mais nova, é isso?

2. R: é

3. Int: a caçulinha?

4. R: caçulinha

5. Int: e você é o caçulinha também?

6. Z: é $^{2 \mathrm{I}}$

Ao mesmo tempo que Anna apresenta este traço discursivo PBLI na Tabela 3, a sua produção apresenta certa insegurança referente à forma a ser usada em uma RC positiva. Esta insegurança pode estar relacionada à dificuldade apresentada na mesma entrevista $\left(\mathrm{A}_{3}-\mathrm{O}_{2}\right)$ em relação à flexão da Ips (Eliasson 2012:107-I09).

Segundo observações feitas por Meisel (200I), crianças bilíngues simultâneas conhecem a gramática de suas duas (ou mais) Lis desde o início, e Meisel diz que a prova deste conhecimento é demonstrada no desempenho da criança ao usar certos fenômenos gramaticais, mesmo que estes apareçam apenas no desempenho de uma de suas línguas (200I:II-I3). Levando em consideração esta afirmação, percebe-se neste exemplo de Anna, que ao se esforçar para falar apenas português limita suas RCs positivas às interjeições $m$, ahã (ahá), $m b u m^{22}$, sendo estas consideradas marcadores conversacionais (MC) suprassegmentais, com a função interacional de marcar a colaboração ou a hesitação do interlocutor (Urbano I995). Agora, o ahã usado como resposta, pode marcar a falta de interesse do ouvinte pelo assunto em pauta, ou distração (Gärtner I998:669). Percebe-se, pela reação da Int na linha 5 (Tabela 3), que o emprego do $m$ : (entonação descendente) acompanhado por ahá causa dúvida quanto ao que Anna realmente quer dizer, se o MC é uma resposta ou uma hesitação com entonação interrogativa. A Int repete a pergunta (gosta?) para confirmar se entendeu o que Anna estava querendo dizer. $\mathrm{Na}$ última resposta deste exemplo, Anna completa o $m$ : (entonação ascendente) afirmativo seguido de uma resposta alargada, na qual retoma os argumentos contidos na pergunta, não deixando dúvidas quanto à sua intenção.

As respostas de Anna podem ser interpretadas como uma estratégia por parte da informante para evitar o confronto com sua dificuldade de se expressar, por entender que não é feito o uso da partícula sim em PB. O uso da partícula sim como resposta afirmativa, poderia ser uma 
transferência da partícula assertiva $j a$ do sueco, mas Anna a evita, indicando ter conhecimento das diferenças encontradas entre os modelos discursivos LFr e LFo.

Maria, por sua vez, apresenta uma produção instável em relação ao uso da LFr na entrevista M2, na qual 35\% dos enunciados são em sueco e $4 \%$ apresentam TC. Observando o registro da curta sequência na Tabela 3, vê-se uma ilustração de como Maria faz uso das RCs em PB.

Esta sequência ilustra o emprego de RCs às interrogativas polares, nas quais se pode encontrar a transferência do sistema sueco ou, então, a implementação do sistema PB. Maria (assim como Anna) usa o MC m: (linha 2, Tabela 3) no lugar de uma RC assertiva verbal, evitando o uso da partícula sim. Na linha 4, Maria afirma usando a partícula assertiva sim, com entonação marcada (descendente), não deixando dúvidas quanto à sua resposta positiva. Apesar de a partícula sim não ser usada como RC positiva, pode ser empregada como confirmação enfática, para confirmar uma denegação anterior, ou então para denegar uma frase declarativa, vindo sempre acompanhada de uma frase verbal, mas não em posição inicial ou sozinha em nenhuma forma do PB (Oliveira 2000:I74-77; Gärtner 1998:666). No caso da resposta de Maria, o uso desta partícula pode ser interpretado como enfático, mas por estar em posição inicial e só, este emprego deve ser considerado desviante. $\mathrm{Na}$ linha 6, a resposta muitos indica o conhecimento de Maria em relação ao modelo empregado no PB pois, restringe-se ao emprego do advérbio por si só, não adicionando a partícula sim, o que teria sido sinal de transferência da LFo neste contexto, onde ja, många (sim, muitos) seria a resposta informal comum usada em sueco.

Apesar de ter sido registrado o emprego da partícula assertiva sim, na linha 2, percebe-se indícios de que Maria já tinha conhecimento da diferença entre os modelos de suas Lis, para o uso das RCs no sueco e no português, mas percebe-se também que encontra dificuldade ao tentar empregá-lo como parte de seu discurso.

\subsection{Segundas entrevistas}

Nas duas entrevistas que compõem a Tabela 4, as meninas tinham acabado de voltar de suas férias de um mês no Brasil na ocasião das gravações.

$\mathrm{Na}$ entrevista $\mathrm{A}_{5}-\mathrm{O}_{3}$ a conversa entre Anna, Oscar e a Int não apresenta muitas ocasiões interativas para o emprego das RCs verbais. As interrogativas polares são poucas, limitando a possibilidade de emprego das partículas afirmativas, ou mesmo das negativas. 
Tabela 4. Exemplos das entrevistas $\mathrm{A}_{5}-\mathrm{O}_{3}$ e $\mathrm{M}_{4}$

\begin{tabular}{|c|c|c|c|}
\hline \multicolumn{2}{|c|}{ Anna (7; I I, 2I) } & \multicolumn{2}{|c|}{ Maria $(6 ; 3,5)$} \\
\hline I. Int: & $\begin{array}{l}\text { e lá no Brasil? como é que foi/ } \\
\text { deu pra falá português? }\end{array}$ & I. Int: & $\begin{array}{l}\text { e faz tempo? cê foi no } \\
\text { cinema no Brasil? }\end{array}$ \\
\hline 2. A: & $\underline{\mathrm{deu}}$ & 2. M: & $\underline{\operatorname{sim}}$ \\
\hline 3. Int: & falou bastante? & 3. Int: & é? \\
\hline 4. A: & $\underline{\text { ahã }}$ & 4. M: & $\underline{\text { eu fui }}$ \\
\hline 5. Int: & é/ com quem que você falou? & & $(\ldots)$ \\
\hline 6. A: & ém: com todos & 5. Int: & cinema dá pra ir aqui, né? \\
\hline 7. Int: & como todo mundo? & 6. M: & $\underline{E}$ \\
\hline 8. A: & ahã, que eu conhece & & \\
\hline
\end{tabular}

$\mathrm{Na}$ linha 2 do exemplo acima, encontra-se, pela primeira vez o emprego de uma RC verbal na fala de Anna. A pergunta que lhe é dirigida na linha I é uma frase interrogativa polar, que poderia ativar o emprego da partícula assertiva sim, mas Anna emprega uma frase verbal usando o verbo finito encontrado na pergunta: $d e u$. O deu apresenta-se aqui, tanto na interrogativa como na resposta, em sua forma genérica, sendo assim impessoal. Este fato não implica na sua forma de emprego no modelo PB para RCs.

Nas linhas 4 (resposta a uma interrogativa de foco largo na linha 3) e 8 (resposta a uma interrogativa de foco estreito na linha 7) encontra-se, mais uma vez, o emprego de ahá como RC nas frases interrogativas polares, onde o emprego de uma RC verbal na linha 4 teria sido o mais adequado no modelo PB: - Falou bastante? - Falei. Enquanto que para a linha 8 a cópula $E$ teria bastado, por ser a interrogativa na linha 7 uma interrogativa de foco estreito ([-IP], no Quadro I): - Todo mundo? - É.

No exemplo I I, a seguir, são registradas duas ocorrências da partícula assertiva sim. Mesmo não tendo encontrado nenhuma ocorrência semelhante no corpus $\mathrm{LI}^{23}$, na qual esta partícula se apresenta como RC, ou então, em posição inicial a uma resposta alargada, observa-se aqui a possibilidade de interpretar estas respostas como indícios de que a aquisição desta forma na linguagem ativa de Anna está seguindo, de forma desviante, para o modelo LI, pois o emprego destas partículas é feito nos mesmos contextos, mas não da mesma forma nos quais o sim ainda é usado no PB: 


\section{( I I)}

I. Int: m:, e lá no Brasil cê ganhou presente?

2. O: m: nã:o

3. A: si:m:

4. Int: da vovó? num ganhou presente da [vovó

5. A: [si:m: ganhou sim

Atualmente, a partícula sim só é empregada em construções denegativas ou em construções enfáticas. Na curta discussão apresentada em (I I), Anna usa a partícula sim para denegar a resposta incorreta de seu irmão (linha 3) e para enfatizar este fato (linha 5) quando a Int retoma a questão. Para seguir o modelo PB de RC, na linha 3, a resposta poderia ter sido: ganhou sim. Enquanto que na linha 5: ganhou, ganhou sim, ou então, ele ganhou sim. A repetição do verbo e o emprego do pronome pleno são duas estratégias usadas no $\mathrm{PB}$ para enfatizar a exatidão da resposta, sendo a partícula sim empregada para marcar ainda mais esta ênfase.

Já em (I 2), Anna usa o modelo enfático do PB para denegar a afirmação de Oscar, empregando o verbo finito encontrado na pergunta e repetindo o mesmo em uma frase complementar alargada:

(I2)

I. Int: tem muita criança?

2. O: [n:ã:o:

3. A: $[$ tem/ tem um dois três quatro cinco

É interessante observar como a fala de Anna apresenta indícios de que a sua linguagem e o emprego do modelo interativo do PB se aproximam do modelo empregado por falantes LI durante a sua estadia no Brasil. Nesta etapa do desenvolvimento da LFr, o emprego das RCs por Anna continua apresentando traços desviantes e mantém o emprego da partícula sim em posição inicial.

Observando agora o desempenho de Maria, no exemplo da Tabela 4, encontra-se apenas uma ocorrência da partícula assertiva sim (linha 2). Esta se encontra como resposta a uma interrogativa polar (linha I) sem apresentar nenhuma função enfática, ou seja, neste caso estaria sendo usada da mesma forma que a partícula assertiva positiva do sueco, ja, podendo assim ser considerada uma transferência do sistema LFo.

Seguindo para a linha 4, na sua resposta à interrogativa da Int, Maria confirma enfaticamente usando o modelo PB (suj+Vfin). Na linha 6, o uso da cópula É confirma a afirmação da Int na linha 5 , bastando a RC É como resposta. 
Apesar de encontrados poucos exemplos na fala de Maria, vê-se indícios de que a informante possa estar empregando uma forma mista dos sistemas LFr e LFo em sua produção da LFr. Ela emprega as frases verbais, mas emprega também a partícula sim em posição inicial em contextos diversos ao modelo PBLI.

\subsection{Terceiras entrevistas}

Depois de Anna ter passado três meses e Maria quatro meses em casa (em Estocolmo), a sua LFr foi novamente registrada. Nas entrevistas A6 e M6 os exemplos encontrados de emprego das RCs, continuou a se desenvolver durante este período no qual o PB volta a ser usado, principalmente, na interação familiar.

Nos exemplos de Anna, na Tabela 5, observa-se a continuidade do desenvolvimento do modelo PB para RCs. Primeiramente, vale observar, nas linhas 2, 4 e 6 um indício de que o emprego das RCs, segundo o modelo $\mathrm{PB}$, passa a fluir na fala da menina:

Tabela 5. Exemplos das entrevistas A6 e M6

\begin{tabular}{|c|c|}
\hline Anna $(8 ; 2,20)$ & Maria $(6 ; 6,13)$ \\
\hline $\begin{array}{l}\text { I. Int: ahã: legal/ dava pra usá no } \\
\text { mar? }\end{array}$ & I. Int: tinha muita criança? \\
\hline 2. A: dava & 2. M: não tanto a:: bara femtitre? \\
\hline 3. Int: num tinha onda não? & 3. Int: quantas? \\
\hline 4. A: $\frac{\text { tinha, mas era muito legal/ }}{\text { tinha ondas muito grandes }}$ & 4. M: femtitre \\
\hline $\begin{array}{l}\text { 5. Int: é mesmo/ e mesmo assim } \\
\text { vocês conseguiram nadá? }\end{array}$ & 5. Int: cinquenta e três? \\
\hline \multirow[t]{3}{*}{ 6. A: } & 6. M: é/ \\
\hline & 7. Int: num é muita criança? \\
\hline & 8. $\mathrm{M}: \quad \underline{\operatorname{sim}}$ \\
\hline
\end{tabular}

O uso do ahá, na linha 6, tem entonação descendente, expressando certeza, diferenciando-se assim dos ahás registrados anteriormente, que deixavam em dúvida a intenção de afirmação da informante, assemelhando-se aos MCs colaborativos ou podendo ser interpretado como distração. 
Em (I3), abaixo, encontra-se na linha 4 o emprego da repetição da partícula sim:

(I3)

I. Int: am: cê fez uma árvore também num fez?

2. A: nã:o num fiz

3. Int: não? naquele que tinha o Mingau/

4. A: [sim, sim]

5. Int: [a namorada] do Mingau nél

6. A: ti:nha

Esta repetição pode ser interpretada como enfática, pois Anna denega uma afirmação feita por si mesma, na linha 2. Quando Anna percebe seu equívoco, arrepende-se concordando enfaticamente com a frase declarativa da $I n t$, na linha 3 . Há aqui uma transferência entre os modelos LFr e LFo, o uso da partícula sim ao invés do emprego da RC verbal. A repetição como ênfase é comum no $\mathrm{PB}$, mas emprega-se, nestes casos, a repetição do verbo finito (Oliveira 2000:I37; Gärtner I998:665) 24. A RC da linha 6 refere-se à declarativa da linha 3, retomando o verbo desta, para mais uma vez afirmar que as interlocutoras estão de acordo, seguindo aqui o modelo PB.

Quanto a Maria, depois de ter passado três meses em Estocolmo, volta a intercalar o sueco com o português em sua interação bilíngue cotidiana, usando $3,5 \%$ de enunciados em sueco e $1,8 \%$ de enunciados mistos (ver Tabela I). No exemplo da Tabela 5, é visto no desempenho de Maria que tem conhecimento do modelo de RCs do PB, mas parece que, ao mesmo tempo, não ter adquirido este modelo por inteiro, pois da mesma forma que intercala o uso do sueco com o português em contexto predominado pela LFr, intercala também o modelo interativo das duas Lis.

Não podemos, porém, negar que tenha havido um desenvolvimento a caminho do modelo LI para RCs na produção de Maria, apesar de seguir um caminho que se diferencia do seguido pelas crianças PBLI.

\subsection{Síntese}

Resumindo a revisão feita nos exemplos aqui apresentados, pudemos observar que Anna e Maria apresentam certa dificuldade em pôr em prática a forma usada para as RCs afirmativas em PB. Indícios de terem conhecimento da diferença entre os modelos de respostas assertivas positivas nas suas duas Lis foram encontrados logo nas primeiras entrevistas. O fato de excluírem o sim de suas respostas, juntamente com o 
emprego exclusivo de MCs afirmativos como resposta positiva às perguntas colocadas pela Int, confirmam a observação de Meisel (I994), na qual se deduz que a criança 2 LI tem conhecimento das regras das suas duas LIs, ou seja, as meninas têm conhecimento das regras gramaticais do PB, mas não produzem este fenômeno na LFr, tendo esta de ser ativada em ambiente PBLI para fazer parte de seu discurso.

Quanto à relação da aquisição da flexão I ps com o desempenho das respostas curtas assertivas, observa-se que o desenvolvimento destes dois fenômenos podem estar interligados. Kato (I994) e Oliveira (2000) assumem as RCs verbais como frases Degree-o (Lightfoot I989), vendo estas frases simples e robustas como o suficiente para que a criança tenha acesso à informação necessária para a aquisição de INFL + pro-drop. No corpus 2 Li observa-se que as crianças adquirem a flexão ips nos três passos aqui registrados (Eliasson 20I2). O mesmo não pode ser dito em relação às RCs verbais. A questão aqui apresenta outro caráter, pois vai além da aquisição da morfossintaxe, apresentando um modelo de emprego dialógico, de interface sintaxe-pragmática. As crianças $2 \mathrm{LI}_{\mathrm{I}}$ têm conhecimento da composição das frases verbais, mas apresentam dificuldade na implementação destas formas. De acordo com Carroll (I989:409):

We would especially expect a lag between the time an item first appears in a child's production and the time where it appears in its correct form in all obligatory contexts a certain percentage of the time.

Constata-se assim que a aquisição da flexão ips apoia o emprego das RCs verbais, mas não é suficiente, pois “é na instanciação dialógica que a criança instaura o exercício metalinguístico do qual [...] depende a aquisição do vocabulário funcional” (Oliveira 2000:236).

Quanto ao modelo de emprego das RCs em geral, foi registrado o emprego da partícula sim em posição inicial em resposta afirmativa, posição esta desviante da norma PBLI. Desde o início observa-se o emprego de MCs em contextos dialógicos que deixavam em dúvida a intenção das informantes, mas no decorrer do período das gravações estas formas deixaram de ser empregadas.

A aquisição das RCs pelas informantes $2 \mathrm{LI}$ apresenta desvios. Encontra-se, de início, um excesso de emprego de MCs ao invés de frases verbais ou da cópula É, além do emprego da partícula sim em posição inicial ou por si só. A partícula sim não é encontrada nas entrevistas que compõem o corpus LI, mas sabe-se da ocorrência desta na fala de crianças PBLI em idade bem precoce (I;09 a 2;02) através dos 
registros de Oliveira (2000). As crianças PBLI passam a usar as formas verbais paralelamente ao uso do sim, sendo que esta partícula já de início aparece acompanhada de uma forma flexionada do verbo, como no exemplo de $\mathrm{R}(\mathrm{I} ; 09,08)$ : As sim (interpretada como Acho sim por Kato (I995) em Oliveira 2000:236). Nem mesmo neste exemplo emprega-se a partícula sim em posição inicial.

A única particularidade da LFo que poderia ter deixado rastros na produção LFr das crianças $2 \mathrm{~L}_{\mathrm{I}}$, teria sido o emprego da partícula sim, mas que não é considerada uma transferência direta do sueco, pois as informantes analisam o seu emprego de acordo com o modelo PB de RC nos exemplos registrados. Percebe-se que há uma preferência, por parte de Maria, em empregar a partícula sim, como influência do sueco, pois apesar de ter conhecimento da sintaxe, não tem prática no emprego do verbo conjugado como RC.

As RCs como fenômeno linguístico já tinham sido registradas antes de sua viagem ao Brasil, mas diferentemente dos fenômenos puramente morfossintáticos, é necessária muita comunicação em ambiente PBLI para que sejam naturalmente produzidas pelas crianças $2 \mathrm{LI}$.

\section{Comentário final}

O intuito deste trabalho foi mostrar que, apesar de nesses casos aqui apresentados, as informantes $2 \mathrm{LI}_{\mathrm{I}}$ crescerem em um ambiente linguisticamente limitado para a aquisição de sua LFr, observamos na sua produção logo nas primeiras entrevistas, o conhecimento da gramática de suas duas Lis. Isso apesar de adquirirem o PB em um ambiente unimonitorado por suas mães, com a colaboração de visitas esporádicas de falantes PBLI, ou de férias no Brasil.

O fato de evitarem certas formas em sua interação poderia ser interpretado como indícios de transferência da LFo, como o emprego das RCs verbais que são substituídas pela partícula assertiva sim, ou mesmo conscientemente evitadas pelas crianças. A interpretação dada a estas estratégias é que os fenômenos já tinham sido acionados e que as crianças são linguisticamente competentes na sua LFr, talvez não tendo capacidade de empregar a forma esperada pelo falante nativo de $\mathrm{PB}$, mas reconhecendo o que não está de acordo com o contexto interacional no qual se encontram.

É possível observar que as frases simples e robustas encontradas no ambiente doméstico bilíngue dos informantes $2 \mathrm{LI}$, se não proporcionam estímulo para todos os parâmetros da LFr, abrem ao menos o 
caminho para a aquisição desta língua, pois acionam a gramática básica da linguagem da criança, aproveitando a plasticidade biológica que a criança pequena possui para a aquisição da linguagem, definindo não apenas a morfossintaxe da LFr, mas também a percepção da criança para esta língua.

\section{Abreviaturas}

$\begin{array}{ll}\text { Ips } & \text { Primeira pessoa do singular } \\ \text { 2LI } & \text { Duas primeiras línguas - bilinguismo simultâneo } \\ \text { Ipp } & \text { Primeira pessoa do plural } \\ \text { AGR } & \text { Agreement } \\ \text { AO } & \text { Age of onset } \\ \text { Fin } & \text { Finito } \\ \text { GG } & \text { Gramática Gerativa } \\ \text { GU } & \text { Gramática Universal } \\ \text { HPC } & \text { Hipótese do Período Crítico } \\ \text { Idade } & \text { Ano;mês;ia } \\ \text { INFL/Infl } & \text { Flexão } \\ \text { Int } & \text { Interlocutora/entrevistadora } \\ \text { LI } & \text { Primeira língua } \\ \text { L2 } & \text { Segunda língua } \\ \text { LFo } & \text { Stronger language - Primeira língua mais forte } \\ \text { LFr } & \text { Weaker language - Primeira língua mais fraca } \\ \text { LH } & \text { Língua de Herança } \\ \text { MC } & \text { Marcadores Conversacionais } \\ \text { MLU } & \text { Mean Length of Utterance } \\ \text { PB } & \text { Português Brasileiro } \\ \text { PBLI } & \text { Português Brasileiro como primeira língua } \\ \text { PC } & \text { Período Crítico } \\ \text { PE } & \text { Português Europeu } \\ \text { PLM } & \text { Português Língua Materna } \\ \text { RC } & \text { Rasposta(s) Curta(s) } \\ \text { S } & \text { Sueco } \\ \text { T } & \text { Tense / tempo verbal } \\ \text { TC } & \text { Troca de código } \\ >\text { trad: } & \text { Tradução } \\ \text { Vfin } & \text { Verbo finito } \\ \text { VP } & \text { Verb phrase - Sintagma verbal } \\ & \end{array}$




\section{Notas}

I. Este artigo é uma versão resumida de um dos capítulos da minha tese de doutorado, "Aquisição bilíngue sueco-português - A produção do português brasileiro como a língua mais fraca em crianças bilíngues simultâneas em Estocolmo", defendida a 2I de maio de 20I2, Departamento de Espanhol, Português e Estudos Latino-Americanos, Universidade de Estocolmo, Suécia.

2. Famílias onde os pais têm diferentes línguas maternas.

3. As crianças pertencem a cinco famílias diferentes, sendo três casais de irmãos e dois filhos únicos (Eliasson 20I 2:26-42).

4. Os fenômenos gramaticais analisados em Eliasson (20I2) foram: a aquisição da concordância verbal de pessoa, a aquisição do emprego das respostas curtas verbais e a aquisição da concordância nominal de número e gênero.

5. Mean Length of Utterance.

6. Os estágios que seguem representam de forma simplificada as fases do desenvolvimento da construção de sentenças: Stage I - MLU I.75; Stage II MLU 2.25; Stage III - MLU 2.75; Stage IV - MLU 3.5०; Stage V - MLU 4.0 (Brown 1973).

7. Troca de Código.

8. $\mathrm{O}$ nome $\mathrm{A}_{3}-\mathrm{O}_{2}$ significa terceira entrevista feita com Anna e segunda com Oscar (seu irmão mais novo). M2: segunda entrevista feita com Maria.

9. A 2 ps é o você, cuja flexão correspondente é a mesma que na terceira pessoa do singular (3ps). A primeira pessoa do plural (Ipp) (nós) também pode estar incluída na flexão 3 ps, como a gente.

IO. Frases tiradas dos exemplos de Oliveira (2000): frase 2 (p. I7I), frase 3 (p. I70) e frase 4 (p. I69).

I I. É interessante observar que esta estratégia afirmativa, o verbo flexionado com o pronome nulo, é empregada em outras línguas também, como o finlandês e o marathi (Holmberg et al. 2009:65-66).

I2. Os comentários entre parênteses são feitos pela autora.

I3. Exemplo adicionado pela autora.

I4. Modelo definido de acordo com três gramáticas prescritivas do sueco: Dahl (I982), Jörgensen \& Svensson (200I) e Teleman et al. (I999a e b).

I 5. O finlandês, assim como o PB, é uma língua de sujeito nulo parcial, mas que, segundo Holmberg (200I), diferencia-se do PB por não haver uma aceitação categórica do sujeito nulo na 3 ps.

I6. Apoiado por Barbosa (2009), Holmberg et al. (2009), Modesto (2004). 
I7. Que por sua vez apóia sua resolução em Kato (I994).

I 8. Há diferentes interpretações deste fenômeno. Modesto (2004) e Holmberg et al. (2009) fazem uma interpretação contrária, na qual defendem o fato de haver a topicalização no $\mathrm{PB}$, este tópico pode ser um constituinte que não é o sujeito da sentença, mas que mesmo assim gera o apagamento do tópico em cadeia, apresentando um sujeito nulo que não tem um sujeito como precedente.

I9. Duarte (2003) discute estar havendo uma mudança nas frases com sujeito expletivo, onde é introduzido um tópico-sujeito para preencher o expletivo, como, por exemplo, o uso do pronome demonstrativo neutro isso, que não atribui informação semântica à sentença, por exemplo: Isso não tem nem dúvida ao invés de Não tem nem dúvida (Duarte 2003:9).

20. Anna nem sempre pronuncia a nasalização do [ã] final, traço este que poderia ser considerado não nativo, mas a pronúncia das crianças 2 LI não será analisada neste artigo.

2I. Temos aqui mais uma ocorrência do emprego da cópula $E$ a uma interrogativa de foco largo por Zé, que confirma assim o conteúdo da frase interrogativa. Como já foi visto, Oliveira (2000:I74) diz que “a copula É está em vias de se transformar em um marcador de polaridade positiva no PB.” Se Zé tivesse usado uma frase verbal como RC, a resposta teria sido sou, focando assim o verbo finito ser da frase interrogativa na linha 5. Agora, segundo Santos (2008:22 I), a criança pode apresentar dificuldade relacionada à sua interpretação da frase interrogativa, focando o verbo da frase subordinada: "A - És tu que vais ganhar? B - Vou.” Vemos isto como uma questão interativa, podendo ocorrer também na fala do adulto, não precisando, necessariamente ser uma má interpretação da frase interrogativa no PB. No exemplo (Io) fica bem claro que Zé não faz essa troca, mostrando que a cópula É pode mesmo estar em vias de se transformar no marcador de polaridade positiva.

22. Vale observar que não emprega a partícula assertiva sim nenhuma vez.

23. A partícula assertiva sim não foi encontrada em contexto semelhante a (II), em nenhum dos outros estudos feitos com crianças PBLI referidos ou consultados em nossa pesquisa.

24. Enquanto que, por exemplo, no PE (Carreira \& Boudoy I993:264; Gärtner I998:667), e em outras línguas românicas como o italiano (Oliveira 2000:I37), a forma usada seria a repetição da partícula sim (ou si), o mesmo acontecendo no sueco (/ja/).

\section{Referências}

Arnberg, Lenore. I98 I. Early childhood bilingualism in the mixed-lingual family. Linköping: Department of education. 
Barbosa, Pilar. 2009. "Two kinds of subject pro”. Studia Linguistica, 63: . 2-58.

Bromn, Roger. I973. A first language: The early stages. London: George Allen and Unvin.

Carreira, Maria Helena Araújo \& Maryvonne Boudoy. I993. Le portugais de $A$ à Z. Paris: Hatier.

Carroll, Susanne. 1989. "Language Acquisition Studies and a Feasible Theory of Grammar”. Canadian Journal of Linguistics, 34:4 • 399-4 I 8.

Chomsky, Noam. I982. Lectures on government and binding: the Pisa lectures. Dordrecht: Foris.

Dahl, Östen. I982. Grammatik. Lund: Studentlitteratur.

Duarte, Maria Eugênia. 2003. "O sujeito expletivo e as construções existenciais”. In: Roncarati, Cláudia \& Jussara Abraçado (eds.). Português brasileirocontato linguístico, heterogeneidade e história. Rio de Janeiro: 7 Letras. I-I3.

Eliasson, Mary-Anne. 20I2. Aquisição bilingue sueco-português - A produção do português como a lingua mais fraca em crianças bilingues simultâneas em Estocolmo. Tese de doutorado, Estocolmo: Departamento de Espanhol, Português e Estudos Latino-Americanos, Stockholms universitet. Disponível online: http://urn.kb.se/resolve?urn=urn:nbn:se:su:diva-75 I 35 (20/06/2013).

Fry, Dennis Butler. I970. "Speech Reception and Perception". In: Lyons, John (ed.). New Horizons in Linguistics. Harmondsworth: Pelican Books. 29-52.

Gärtner, Eberhard. I998. Grammatik de portugiesischen Sprache. Tübingen: Niemeyer.

Heuninck, Ronald. I989. Utelekar. Järna: Balder.

Holmberg, Anders. 200I. "The Syntax of Yes and No in Finnish". Studia Linguistica, 55:2. I40-I74.

Holmberg, Anders, Aarti Nayudu \& Michelle Sheehan. 2009. "Three Particial Null-subject Languages: a comparison of Brazilian Portuguese, Finnish and Marathi”. Studia Linguistica, 63:I. 59-97.

Hyltenstam, Kenneth. I999. "Inledning: Ideologi, politik och minoritetsspråk”. In: Hyltenstam, Kenneth (ed.). Sveriges sju inhemska språk - ett minoritetsspråksperspektiv. Stockholm: Studentlitteratur. I I-40.

Jörgensen, Nils \& Jan Svensson. 200I. Nusvensk grammatik. 2a ed, Malmö: Gleerup.

Kato, Mary. I994. "A Theory of Null Objects and the Development of a Brazilian Child Grammar”. In: Tracy, Rosemarie \& Elsa Lattey (eds). 
How Tolerant Is Universal Grammar? : essays on language learnability and language variation. Tübingen: Niemeyer (Linguistische Arbeiten; 309). I 25 -I 54 .

Kato, Mary. I995. Functional Categories and the Full Competence Hypothesis. Paper apresentada no Instituto de Estudos Avançados. Universidade de São Paulo São Sebastião.

Kato, Mary. 2002. A Evolução da Noção de Parâmetros. D.E.L.T.A., I8:2. 309-337.

Lemos, Cláudia Guimarares de. 1975. The use of ser and estar with particular reference to child language acquisition. Doctoral Thesis. Edinburgh: University of Edinburgh.

Lightfoot, David. I989. “The child's trigger experience: Degree-o learnability”. Behavioral and Brain Sciences, I2. 32 I-334.

Lightfoot, David. \& Marit Westergaard. 2007. "Language Acquisition and Language Change: Inter-relationships". Language and Linguistics Compass, I: $5,396-405$.

Lund, Mary-Anne. 2003. A lingua é minha pátria. Análise dos sintomas de atrição linguistica primária referente ao uso do português por brasileiros residentes em Estocolmo. Master's Thesis. Stockholm: Stockholms universitet. Disponível online: http://urn.kb.se/resolve?urn=urn:nbn:se:su:diva-7I044 (20/06/20I3).

Meisel, Jürgen. I994. "Getting FAT: Finiteness, Agreement and Tense in Early Grammars". In: Meisel, Jürgen (ed.). Bilingual first language acquisition: French and German grammatical development. Philadelphia/Amsterdam: Benjamins. 89-I 29.

Meisel, Jürgen. 200I. "The simultaneous acquisition of two first languages". In: Cenos, Jasone \& Fred Genesee (eds.). Trends in bilingual acquisition. Amsterdam: Benjamins. I I-4I.

Mioto, Carlos, Maria Cristina F. Silva \& Ruth Lopes. 2010. Novo Manual da Sintaxe. 4 a edição. Florianópolis: Editora Insular.

Modesto, Marcello. 2004 “Sujeitos Nulos em Línguas de Tópico Proeminente”. Revista da ABRALIN, 3:I. II9-I45.

Oliveira, Marilza de. 2000. Frases assertivas sua variação nas línguas românicas: seu papel na aquisição. São Paulo: Humanitas.

Pinker, Steven. 1984. Language Learnability and Language Development. Cambridge: Harvard University Press. 
Pires, Acrísio \& Jason Rothman. 20I r. "An integrated perspective on comparative bilingual differences - Beyond the Interface problem?" Linguistic Approaches to Bilingualism, I:I. 74-78.

Schlyter, Suzanne. 1987. "Language mixing and linguistic level in three bilingual children". Scandinavian Working Papers on Bilingualism, 7. 29-48.

Schlyter, Suzanne. I993. "The weaker language in bilingual Swedish-French children". In: Hyltenstam, Kenneth \& Åke Viberg (eds.). Progression and regression in language: Sociocultural, neuropsychological, \& linguistic perspectives. Cambridge: Cambridge University Press. 289-308.

Schlyter, Suzanne. I994. "Early morphology in Swedish as the weaker language in French-Swedish bilingual children". Scandinavian Working Papers on Bilingualism, 9. 67-86.

Sorace, Antonella \& Ludovica Serratrice. 2009. "Internal and external interfaces in bilingual language development: Beyond structural overlap". International Journal of Bilingualism, I3:2. 195-2 10.

Teleman, Ulf, Staffan Hellberg, Erik Andersson \& Lisa Christensen. I999. Svenska akademiens grammatik - 4: Satser och meningar. Stockholm: Svenska akademien.

Urbano, Hudinilson. I995. "Marcadores Conversacionais". In: Preti, Dino (ed.). Análise de textos orais, $2^{a}$ edição, São Paulo: FFLCH/USP. 8 I-ıо .

Yukawa, Emiko. I997. Li Japanese attrition and regaining: three case studies of two early bilingual children. Doktorsavhandling [Tese de doutorado]. Stockholm: Centre for Research on Bilingualism Centrum för tvåspråkighetsforskning, Stockholm University. 